\title{
Impacts of helmet law on the changes in potential years of life lost due to traffic injury: a multiple- province evaluation in Vietnam
}

\author{
Dung Phung, ${ }^{1,2} \mathrm{Ha}$ Trong Nguyen, ${ }^{3}$ Cordia Chu, ${ }^{2}$ Ross Sadler, ${ }^{2}$ Anh Mai Luong, ${ }^{4}$ \\ Huyen Thi Nguyen, ${ }^{4}$ Tuan Cong Pham, ${ }^{\circ 2}$ Huang Cunrui ${ }^{1}$
}

- Additional material is published online only. To view please visit the journal online (http://dx.doi.org/10.1136/ injuryprev-2018-043088).

${ }^{1}$ Health Management and Policy, School of Public Health, Sun Yat-Sen University, Guangzhou, China ${ }^{2}$ School of Medicine Griffith University, Brisbane, Queensland, Australia ${ }^{3}$ Injury Division, The George Institute for Global Health, Sydney, New South Wales, Australia

${ }^{4}$ Vietnam Health Environment Management Agency, Ministry of Health, Hanoi, Vietnam

\section{Correspondence to} Dr Dung Phung, School of Medicine, Griffith UniversityGold Coast Campus, Southport, QLD 4215, Australia; d.phung@ griffith.edu.au

Received 24 November 2018 Revised 7 January 2019 Accepted 12 January 2019

\section{Check for updates}

(C) Author(s) (or their employer(s)) 2019. No commercial re-use. See rights and permissions. Published by BMJ.

To cite: Phung D, Nguyen $\mathrm{HT}_{\text {, }}$ Chu C, et al. Inj Prev Epub ahead of print: [please include Day Month Year]. doi:10.1136/

injuryprev-2018-043088

\begin{abstract}
Introduction This study aimed to evaluate the impact of the helmet law on the changes in potential years of life lost (PYLL) due to traffic mortality and to examine modification effects of socioeconomic factors on the impacts in Vietnam
\end{abstract}

Methods We applied an interrupted time series design using the Bayesian framework to estimate the impact of the law at the provincial level. Then, we used random effects meta-analysis to estimate the impact of the law at the country level and to examine the modification effects of socioeconomic factors.

Results The results indicate that the impacts varied among the provinces. These impacts could be classified by four main groups comprising positive impact, and positive impact without sustainability, possible positive impact, negative or inconsistent impact. For the countrylevel impact, the results reveal a significantly consistent change in monthly PYLLs at the level of 18 per 100 000 persons, and the post-trend was stable without significant change. The results of meta-regression show that 1 unit increase in the population density (persons/ $\left.\mathrm{km}^{2}\right)$, migration rate (\%) and income ( $\times 1000$ dong) are non-significantly associated with increases of PYLLS at 1.3, 27 and 27 per 100000 person-months, respectively, whereas 1\% increase in literacy associated with a decrease of PYLL at 44 per 100000 person-months. Discussion Further studies should be warranted to provide a comprehensive evaluation of the law implementation, including its acceptability, adoption, appropriateness, feasibility, cost-effectiveness and sustainability.

\section{INTRODUCTION}

Road traffic injuries (RTIs) cause a major public health burden and developmental crisis. ${ }^{1}$ A total of 1.2 million fatalities occurs each year on the world's roads and millions more are suffering serious injuries and living with long-term adverse health consequences. ${ }^{2}$ Road safety is a particular concern in Lower- and Lower Middle-Income Countries (LICs and LMICs) due to rapid and unplanned urbanization, the absence of adequate infrastructure in urban cities, and the lack of a sufficient regulatory framework. ${ }^{12}$ In terms of economic burden, RTIs contribute the greatest proportion, costing more than US $\$ 500$ billion per year, among all types of injuries. ${ }^{3}$ The study by Dalal et al (2013) revealed that the trend of DALYs and deaths due to RTIs were still increasing
LICs and LMICs, and the economic loss due to RTI related Disability-Adjusted Life Year (DALYs) in LICs was almost 33 times greater than that in high-income countries. ${ }^{4}$ Motorcyclists are among the most vulnerable road users and at higher risk of injury and mortality. ${ }^{5}$ High-quality and certified motorcycle helmets have been clearly illustrated to reduce the incidence of injuries in countries worldwide. ${ }^{78}$ Nevertheless, the helmets are still underused in LMICs where motorcycles have been the primary means of transport. ${ }^{9}$

In Vietnam, the motorcycle is the most common means of transport, accounting for $95 \%$ of registered road traffic vehicles ${ }^{10}$; and the number of registered motorcycles increased to 37 million in $2013 .^{11}$ RTC results in about 14000 deaths annually, and $70 \%$ of which are related to motorcyclists. The resulting cost was $2.5 \%$ of the gross domestic product in 2010, a significant economic burden to society. ${ }^{12}$ Regarding the burden to the victims and their families, costs of road traffic injury (RTI) during hospitalisation period were estimated at US\$363 per injury, or 6 months of an average salary. $^{13}$

To address the burden of RTIs related to motorcyclists, helmet law was first introduced in Vietnam in 2001. However, the usage was limited due to low compliance, inadequate enforcement and restricted application (only mandatory when riding on national and provincial highways). ${ }^{14}$ In June 2007, the Government of Vietnam passed a stringent law, making the wearing of helmet compulsory for rider and passenger on all roads effective 15 December 2007. Offenders would face a fine of US\$6-US\$12, an equivalent to approximately $30 \%$ of an average monthly income. ${ }^{1516}$

Research suggests that the law's passage saved more than 1500 lives the following first year and decreased serious head injuries by approximately $2500 .{ }^{17} \mathrm{Ha}$ et $a l^{6}$ found that motorcycle-related injuries and deaths reduced by $47 \%$ and $31 \%$, respectively, in a district in Vietnam after the implementation of the 2007 mandatory helmet law. ${ }^{6}$ Olson et al indicated that the introduction of helmet policy was likely preventing 2200 deaths and 29000 head injuries, saved US\$18 million in acute care costs and averted US\$31 million in income losses in Vietnam. ${ }^{18}$ While prior studies provided valuable information on the effect of the 2007 helmet law, the temporal trend of changes in traffic injuries following the effective date of the 
law and the variability of changes across provinces has been unknown.

The objectives of this study are to evaluate the impact of the helmet law in the spatiotemporal changes in potential years of life lost (PYLL) due to RTIs in Vietnam and the modification effects of socioeconomic factors on the impacts of the helmet law.

\section{METHODS}

\section{Data sources and data items}

RTI mortality data were sourced from the A6 mortality reporting system, maintained by the Division for Occupational and Injury Prevention from the authors' institute. The A6 mortality reporting system was established within the health system and the primary source of mortality data for the Ministry of Health since 1992. ${ }^{19}$ The evaluations by Stevenson et al revealed that the A6 system is a valuable resource for identifying and planning preventive strategies targeting the leading causes of injury-related deaths in Vietnam. ${ }^{20} 21$ Data items extracted include age of death due to RTI (International Classification of Diseases-Tenth Revision codes of V01-W99), month and year of death, and their province of residence. The date range of the data extracted is from 1 January 2005 to 31 December 2009 for 63 provinces in Vietnam. Data on the socioeconomic status (SES) of provinces were retrieved from the website of the General Statistics Office of Vietnam ${ }^{22}$ comprising population density (persons per $\mathrm{km}^{2}$, per-capita income (1000 dong), in-migration rate (\%), literacy (\%) and the number of road passengers (persons)).

\section{Measurements of variables}

We computed monthly PYLLs, the dependent variable, as the total number of PYLLs in each month divided by the total population of the corresponding year. In estimating the PYLLs, we used the life average expectancy of years 2005 and 2009 for each geographical region reported in the Vietnam National Census 2009. The law effective date (LED) was December 2007. Time before-the-law variable, which is used to examine the baseline trend of PYLLs before the LED, is an ordinal variable indicating time in months from the start of the observation period to the LED (Time $_{\mathrm{i}}=0$ at January 2005); Law variable, which is used to evaluate the change in PYLLs after the LED, is a categorical variable ( $\mathrm{Law}=0$, before the $\mathrm{LED}$, and $\mathrm{Law}=1$, after $\mathrm{LED})$; Time after-the-law variable is an ordinal variable indicating time in months from the start of the LED; and MOYs are dummy variables for month of a year which are used to control the potential seasonal effect on PYLLs.

\section{Data analysis}

First, we used an interrupted time series (ITS) design ${ }^{23}$ with segmented regression analysis using Bayesian framework to measure the impact of the 2007 helmet law by quantifying the change (the y-intercept) and trend (the slope) of the monthly PYLLs (/100 000) over 6 months after the LED. To model the effects of multiperiod interventions and to avoid incorrect specification of intervention effects, we excluded from the analysis the monthly PYLLs (/100 000) of the month within the lag or 'during the law' period. For example, PYLLs for month 0 (December 2007) and month 1 (January 2008) were excluded when estimating the impact of the law on month 2 (February 2008). Equation 1 below is the model fitted to measure the impact of the law at the provincial level.

$$
\begin{aligned}
Y= & \beta_{0}+\beta_{1} \times \text { Time before the LED }+\beta_{2} \times \text { Law } \\
& +\beta_{3} \times \text { Time after the LED }+M O Y_{i}
\end{aligned}
$$

In this model, $\beta_{0}$ is constant, $\beta_{1}$ is the estimated change in the monthly PYLLs (/100 000), which occurs before the LED (ie, baseline level). 'Time before-the-law' variable is an ordinal variable indicating time in months starting from the beginning of the observation period to the LED (Time before-the-law $=0$ at January 2005). $\beta_{2}$ is the estimated change in the monthly PYLLs (/100 000) immediately after the 'lag' months following the LED. 'Law' variable is a categorical variable ( $\mathrm{Law}=0$, before the LED, and Law $=1$, after the LED). $\beta_{3}$ is the estimated change in the trend of the monthly PYLL (/100 000) after the LED,

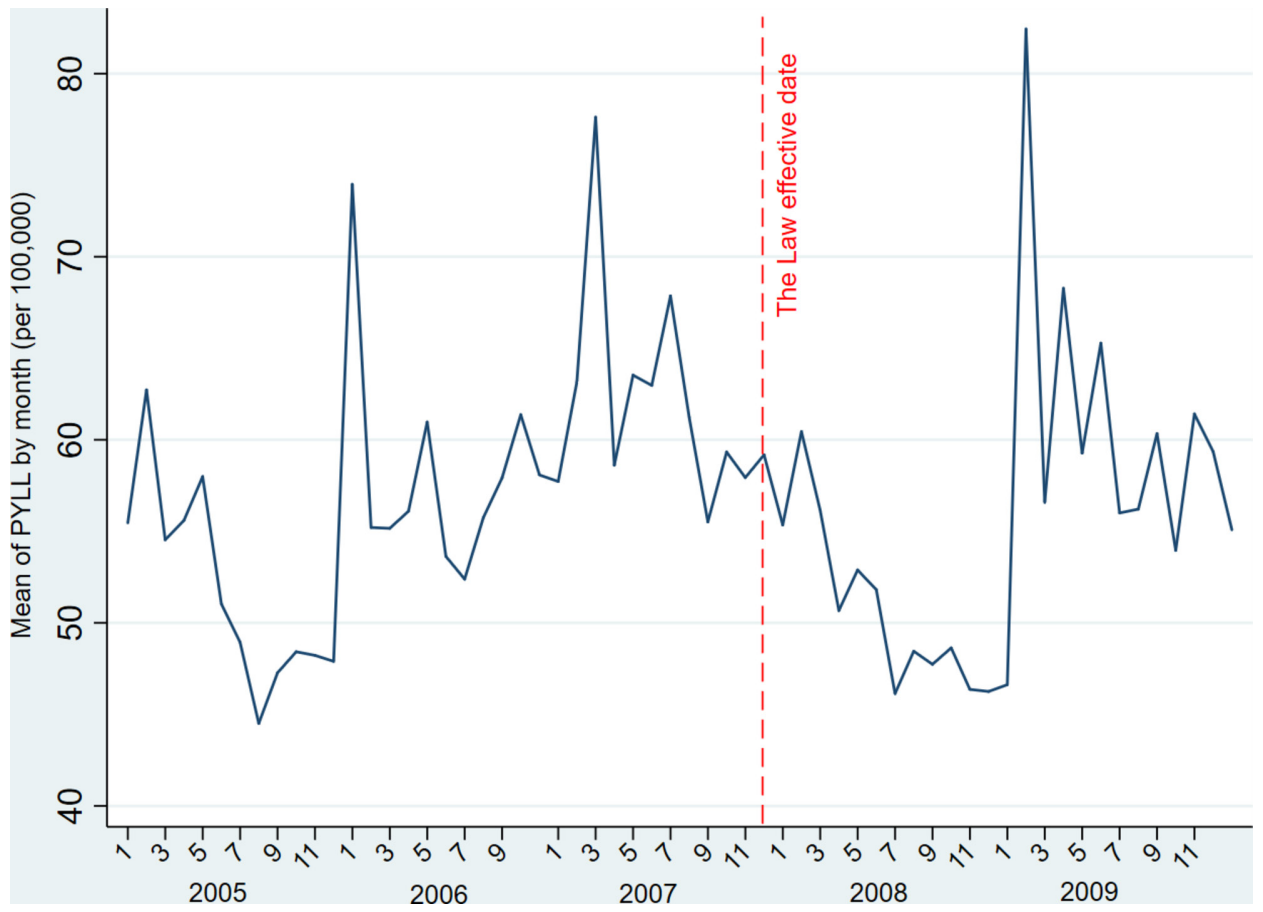

Figure 1 Mean of potential years of life lost (PYLL) (per 100 000) by month. 

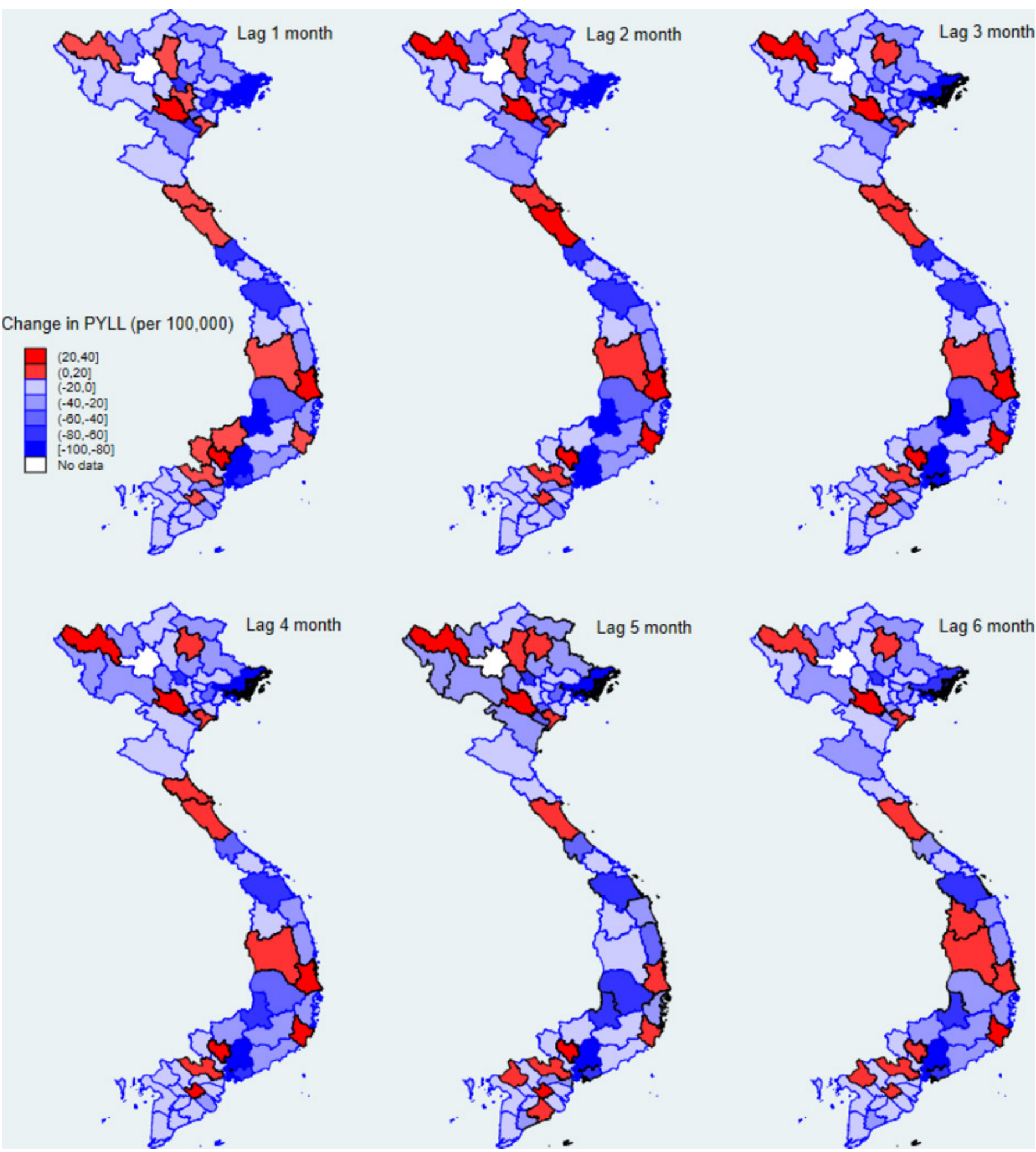

Figure 2 Changes in monthly potential years of life lost (PYLL) (per 100000 person-months) after the effective date of the law.

compared with the monthly trend before the LED. 'Time afterthe-law' variable is an ordinal variable indicating time in months starting after the 'lag' month(s) following the LED. 'MOYs' are dummy variables for month of a year which are used to control for the potential seasonal effect on the monthly PYLLs (/100 000).

To categorise the types of impact of the 2007 helmet law, we grouped provinces into four types of impact based on their trend over time of PYLLs (/100 000) during the periods before and after the LED. The first is a 'sustained positive impact' category, which was reflected by a decrease in the monthly PYLLs (/100 000) after the LED and the trend of monthly PYLLs (/100 000) after 6 months following the LED stayed downward while the trend was increased or unchanged before the law. The second category is an 'un-sustained positive impact', which was characterised by an immediate decrease in monthly PYLLs (/100 000) after the LED and followed by an upward trend in monthly PYLLs (/100 000) after months following the LED. The third 


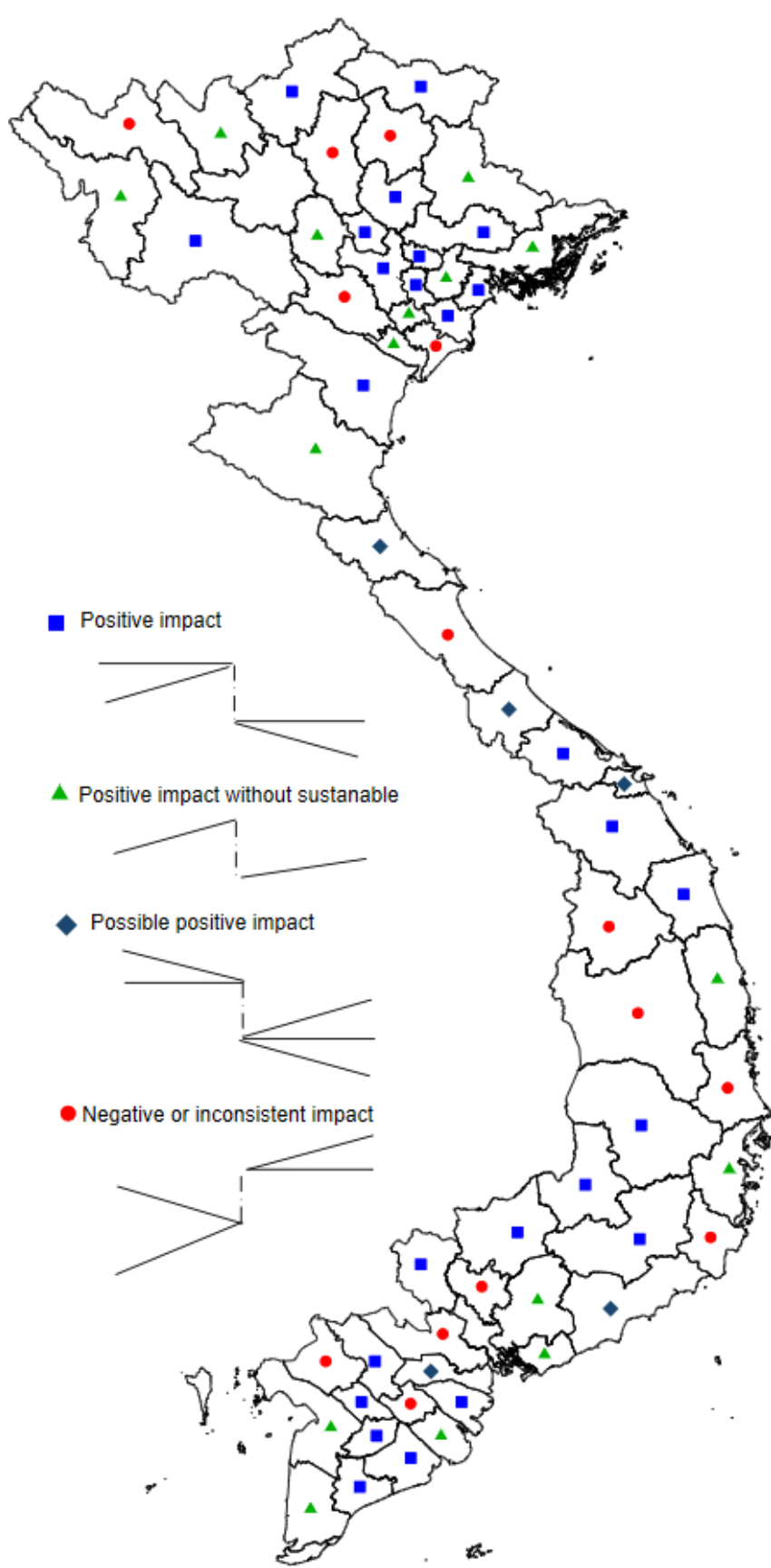

Figure 3 Trends of potential years of life lost (PYLL) before and after the law effective date.

category is a 'possible positive impact' of the law, which was reflected by an immediate decrease and a permanent downward trend in PYLLs after months following the date the law came into effect while the trend was also decreased before the law. A 'negative or inconsistent impact' reflects by an increase and permanent upward trend or no change in PYLLs after months following the law's effective date.

We also used meta-analysis to calculate the pooled estimates of the country-level impact of the law on the PYLLs. Because the impact of the law might vary among provinces due to the variability of the population and socioeconomic factors, resulting in considerable heterogeneity of findings, a random effects meta-analysis was applied to compute within-province and between-province variation and generated the pooled estimated of changes in level and trend of PYLLs. The pooled estimates of effect sizes were calculated for each month after the LED over 6 months. Heterogeneity between provinces was quantified by the coefficient of inconsistency $\left(\mathrm{I}^{2}\right)$, which describes the percentage of total variation across provinces that is due to heterogeneity rather than chance. ${ }^{24}$

To examine the modification effects of socioeconomic factors on the changes in PYLL of 6 months following the LED, we used the random effects meta-regression. The model included the 6-month changes as a dependent variable and socioeconomic factors as independent variables. The meta-regression equation is shown below. All the data analyses were conducted using Bayes and meta-analysis statistical packages of Stata V.15.0 (StataCorp. 2017. Stata Statistical Software: Release 15. College Station, TX).

$$
Y=\beta_{i} \sum S E S_{i}+\varepsilon
$$

where $Y$ is change in PYLLs following 6 months after the LED; $S E S_{i}$ is the socioeconomic factor I; $\beta_{i}$ is the change in $Y$ corresponding to change in $S E S_{i}$; and $\varepsilon$ specifies the between-province variation.

\section{RESULTS}

Between 1 January 2005 and 31 December 2009, there were 76 306 deaths due to RTIs recorded by the A6 mortality reporting system, equivalent to a total of 2712759 PYLLs in all 63 provinces in Vietnam. One province was excluded because it had less than 12 months of PYLL data after the LED. The monthly PYLLs (/100 000) varied from 23.6 to 129.7 across provinces with a mean of 56.4. The three provinces with highest PYLLs (/100 000) were in the central region of Vietnam (including $\mathrm{Ha}$ Tinh province, 109.6; Quang Tri province, 129.7; and Binh Thuan province, 113.9 PYLLs per 100 000. In terms of temporal distribution, the monthly PYLLs per 100000 decreased sharply after the effective date of the law (December 2007) (figure 1).

The changes in the mean monthly PYLLs (/100 000) between the period before the law and the period after the law with a lag time of 1-6 months are shown in figure 2 . The percentage of provinces having a reduction in PYLLs increased from $78 \%$ (48 provinces) after 1 month to $82 \%$ (51 provinces) after the period of 2-6 months after the LED, respectively. Among these 51 provinces, the decreases in the level of PYLLs ranged from 2.9 to $92.4,0.9$ to $89.1,0.2$ to $86.3,0.1$ to $87.6,3.7$ to 87.5 and 1.7 to 82 PYLLs per 100000 for 1, 2, 3, 4, 5 and 6 months after the LED, respectively. In three provinces, Tuyen Quang, Binh Phuoc and Tay Ninh, reduction in PYLLs was only observed from 4 months after the LED. The remaining 12 provinces had no reduction in PYLLs for the entire period after the LED (figure 2).

In terms of types of impacts, the provinces are classified in four main groups. Group 1 comprises 26 provinces (41\% with the total population of 44866298 ) where we identified a 'positive impact'. Group 2, which is identified as 'unsustained positive impact', comprises 16 provinces $(25 \%$ with the total population of 20624040$)$. Group 3 comprises five provinces ( $8 \%$ with the total population of 5552 091) being considered as 'possible positive impact'. Group 4 comprises 14 provinces (22\% with the total population of 14064 171) being considered as 'negative or inconsistent impact' (figure 3). These effects were observed regardless of what trend in PYLLs was observed before the LED in these provinces. The details of changes in level and trend of PYLLs by provinces and months are reported in online supplementary file.

For the impact at the country level, table 1 shows the pooled estimates of the monthly PYLLs per 100000 by the number of 
Table 1 Country-level effects: a meta-analysis

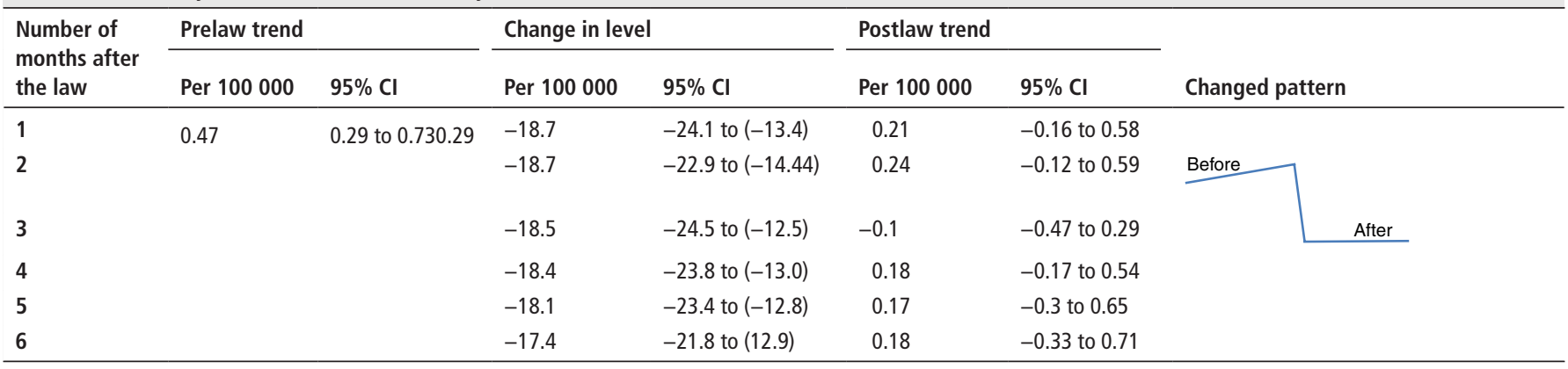

months before (prelaw trend) and after (postlaw trend) the LED. The results indicate significantly consistent changes in the level of PYLLs at about 18 per 100 000; the post-trend was stable with minor fluctuation following 6 months of the date the law came into effect; whereas the trend in PYLLs before that date was significantly increased at the level of 0.47 per 100000 (table 1).

The potential modification effects of socioeconomic factors on the impacts of the law are shown in table 2. These effects are reflected by the change in the levels of PYLLs corresponding to the change in units of the factors of SES. The results of meta-regression indicate that 1 unit increase in the population density (persons $/ \mathrm{km}^{2}$ ), migration rate $(\%)$ and per-capita income $(\times 1000$ dong) associated with increases of PYLLs at 1.3, 27 and 27 per 100 000, respectively. On the other hand, 1\% increase in literacy was associated with a decrease of PYLL at 44 per 100 000 . However, these associations were not statistically significant and need to be further investigated.

\section{DISCUSSION}

This is the first study to quantitatively evaluate the impact of helmet law at the national scale using an ITS approach, in which approach is considered the strongest quasiexperimental method to assess the effectiveness of population health interventions ranging from clinical therapies to national public health legislation. $^{25}$ The impact of the helmet law was measured in terms of PYLLs per 100000 populations due to RTIs. The analyses were carried out at national and provincial levels. The results at the national level show that the 2007 helmet law was associated with a significant reduction in the monthly PYLL. At the provincial level, the results indicate that the impacts of helmet law varied by provinces, which are considered by the four groups: 'positive impact', 'unsustained positive impact', 'possible positive impact' and 'negative and inconsistent impact'. This might reflect the differences in implementing the helmet law due to divergence in resource capacity among provinces.

The reduction in traffic-related PYLLs found in our study highlights the importance of the helmet law. A systematic review by Peng et al reported that implementing universal helmet laws in the USA increased helmet use by $47 \%$ and reduced total injuries by $32 \%$ and injuries per registered motorcycle by $29 \%{ }^{26}$ Another study by Lee reveals that lives saved from the helmet law in the USA were estimated to be associated with an aggregated life yield value of approximately US\$940 million. ${ }^{27}$ The studies in Asia and Europe also consistently demonstrated that wearing a helmet reduces the risk of death, craniocerebral trauma and facial injuries by up to one-half. ${ }^{28}$ The positive impact of helmet legislation could be attributed to the technological efficacy of helmets as well as reduced risk-taking behaviour among motorcyclists when they wear a helmet. ${ }^{27}$

Several factors were demonstrated to influence on the variety of impacts of the helmet laws. A review by Urie et al indicated that education and culture play important roles in improving the efficacy of law enforcement such as seat belts and the helmet law, and the present study expressed that taking into account culture and education is a key aspect in improving road safety. ${ }^{29}$ For instance, studies in Greece identified that education and culture were the primary reasons for non-compliance to the willingness to wear seat belts and helmets. The number of years of education, alcohol consumption and time of day when riding occurred were found to be significant predictors of the frequency of self-reported helmet use. ${ }^{30}$ Another study by Haqverdi et al in Iran reveals that safety belief, norms, risky traffic behaviour and awareness of traffic rules were found to be key determinants of helmet use, and the study called improvements in safety training and courses towards motorcyclists. ${ }^{32}$ In an examination of factors associated with the use of helmets following enactment of the helmet law, the authors demonstrated a wide variety of factors influencing helmet use across demographic segments of the motorcyclist population. Of these factors, race and age were found to be significantly associated with the rate of helmet use. Use of helmets was also found to be highly divergent geographically, temporally and with respect to various environmental characteristics. These factors were likely to be correlated with historical restraint use trends, which may be reflective of riding environment and general differences in the riding population. ${ }^{33}$ Such findings can be considered as evidence to explain

Table 2 Estimated change in the impacts of the helmet law (PYLLs) per unit change in province-level sociodemographic factors

\begin{tabular}{lcc}
\hline Province-level sociodemographic factor & Unit change in predictor & $\begin{array}{l}\text { Change in the slope of the law-PYLLs (per 100 000) } \\
\text { (95\% Cl) }\end{array}$ \\
\hline Population density (persons $\left./ \mathrm{km}^{2}\right)$ & 1000 & $1.4(0$ to 3.2$)$ \\
\hline In-migration rate (\%) & 1 & $27(-0.5$ to 33$)$ \\
Family income (VND) & 1000 & $28(-0.6$ to 47$)$ \\
Literacy (\%) & $1 \%$ & $-40(-85$ to 121$)$ \\
Road passengers & 1000 & $-0.1(-0.5$ to 1$)$ \\
\hline
\end{tabular}

PYLL, potential years of life lost; VND, Vietnamese dong. 
the divergence in changes in PYLLs after the helmet LED, since provinces in Vietnam have big differences in geographical, environmental and cultural characteristics.

Our study has some advantages. First, in measuring outcome in terms of PYLLs, the burden of mortality could also take into account the age of death in addition to the number of deaths, commonly reported in previous studies. ${ }^{6} 1834$ Second, the study reported the changes in the PYLLs before and after the helmet law and the trend of PYLL over 6 months following the effective date of the law. Third, the study examined the impacts of the helmet law across all provinces and then pooled estimates of the impact at the national level; whereas the previous work did the evaluation at the sample locations but not throughout the country.

The present study has some limitations. First, due to the nature of secondary data, we were unable to validate the quality of data such as inclusion of deaths, and we also missed the subclassifications of death due to RTIs. However, the previous studies $^{2021}$ indicated that the mortality data provided from A6 system were highly reliable for injury-related studies. Second, the routine data did not include household characteristics and individual factors (eg, race, occupation, safety behaviour, and so on), and extreme event-related issues (eg, disasters, flooding, extremely heavy rainfall) which might associate with the risk of traffic-related injuries, so this limited a consideration on the potential factors on the impacts of the helmet law. However, these factors are expected to be changed in a long-term but not in the short-term period. Third, we were unable to obtain data on community safety programmes which have been implemented by international organisations and non-governmental organisations, so the added or interactive effects of these programmes were not considered in the data analysis. Further studies should be implemented to understand how community promotion programmes make a contribution in enhancing the effectiveness of the law. Qualitative study design, which is integrated into a mixed method with a quantitative design like our study, will be a useful tool to investigate these why and how questions.

\section{What is already known on this subject}

- The passage of 2007 mandatory helmet law in Vietnam had prevented head injuries and death among motorcycle riders.

- The efficacy of the helmet law on reducing the fatalities due to traffic injuries has been approved in a few small-scale studies in Vietnam.

\section{What this study adds}

- The first study evaluated the efficacy of the helmet law on the potential yYears of life lost (PYLL) due to traffic injuries across Vietnam.

- The introduction of helmet law had led to a significantly consistent reduction of 18 PYLLs per 100000 persons due to traffic-related injuries monthly in Vietnam.

- The impacts of the helmet law varied by provinces with four categories, comprising: positive impact, and positive impact without sustainability, possible positive impact, negative or inconsistent impact.

\section{CONCLUSION}

The mandatory helmet law for motorcycle rider and passenger to wear a helmet on all roads from 15 December 2007 across Vietnam resulted in a significant reduction in PYLL as regards public health. The outcomes were investigated using a robust study design with an advanced quasiexperimental analysis. The study revealed significant impacts of the helmet law on reducing the mortality burden of traffic-related injuries at the country level. While the impact varied across provinces, sustainable positive outcomes of the law were observed in the majority of provinces. From the perspective of the present study (impact of the law at the ecological level), further studies need to identify ecological factors that undermine the positive impacts of the helmet law. Moreover, more studies should also be conducted to provide a comprehensive evaluation on the law implementation, including its acceptability, adoption, appropriateness, feasibility, cost-effectiveness and sustainability at the provincial level, particularly in Vietnam

Funding DP was supported by the research fellowship from Sun Yat-Sen University, China.

Competing interests None declared.

Patient consent for publication Not required.

Provenance and peer review Not commissioned; externally peer reviewed.

\section{REFERENCES}

1. WHO. World report on road traffic injury prevention. edited by Margie Peden, et al. World Health Organization, Geneva 2004.

2. WHO, 2013. Global status report on road safety. Available: http://www.who.int/ violence_injury_preventation/road_safety_status/2013/en/index.html [Accessed 15 Sep 2018]

3. Gosselin R, Spiegel DA, Coughlin R. Injuries: the neglected burden in developing countries. Bull World Health Organ 2009;87.

4. Dalal K, Lin Z, Gifford M, et al. Economics of global burden of road traffic injuries and their relationship with health system variables. Int J Prev Med 2013;4:1442-50.

5. Solagberu BA, Ofoegbu CKP, Nasir AA. Motorcycle injuries in a developing country and the vulnerability of riders, passengers, and pedestrians. Inj Prev 2006;12:266-8

$6 \mathrm{Ha}$ NT, Ederer D, Vo VAH, et al. Changes in motorcycle-related injuries and deaths after mandatory motorcycle helmet law in a district of Vietnam. Traffic Inj Prev 2018;19:75-80.

7. Chiu WT, Kuo CY, Hung CC, et al. The effect of the Taiwan motorcycle helmet use law on head injuries. American journal of public health 2000;90:793-6.

8. Ichikawa M, Chadbunchachai W, Marui E. Effect of the helmet act for motorcyclists in Thailand. Accid Anal Prev 2003;35:183-9.

9. Craft G, Van Bui T, Sidik M, et al. A comprehensive approach to MotorcycleRelated head injury prevention: experiences from the field in Vietnam, Cambodia, and Uganda. International Journal of Environmental Research and Public Health 2017; 14.

10. LC L, Blum RW. Road traffic injury among young people in Vietnam: evidence from two rounds of national adolescent health surveys, 2004-2009. Global Health Action 2009;6.

11. Ministry of Transport, 2013. Number of transportations registered. Available: http:// mt.gov.vn/vn/tin-tuc/13956/so-lieu-phuong-tienco-gioi-duong-bo-dang-ky-moi.aspx [Accessed 31 Jul 2018].

12. Ivers RQ, Nguyen HT, La QN. Status of road safety and injury burden. J Orthop Trauma 2014;28:S50-S51.

13. Nguyen $H$, Ivers $R Q$, Jan $S$, et al. The economic burden of road traffic injuries: evidence from a provincial General Hospital in Vietnam. Inj Prev 2013;19:79-84.

14. Pervin A, Passmore J, Sidik M, et al. Viet Nam's mandatory motorcycle helmet law and its impact on children. WHO Bulletin 2009;87:369-73.

15. GoSRo V. Resolution on a number of urgent countermeasures to curb traffic safety and alleviate traffic congestion [Resolution number 32/2007/NQ-CP] 2007.

16. MoP S. Guidance on the implementation of certain article in decree 146/2007/ND-CP of the government on the application of civil fines in road traffic (circular number 23/2008/TT-BCA-C11 dated 14 October, 2008);2008.

17. Enserink M. Hats off to Vietnam's helmet law. Science 2014;345:1261.

18. Olson Z, Staples JA, Mock C, et al. Helmet regulation in Vietnam: impact on health, equity and medical impoverishment. Inj Prev 2016;22:233-8.

19. Ministry of Health. Decision no 2554/BYT.QD to issue mandatory and active registration in developing health information at commune health Station, district health center and provincial health department. Hanoi, Vietnam, 2002. 
20. Stevenson MR, Ngoan leT, Hung DV, et al. Evaluation of the Vietnamese A6 mortality reporting system: injury as a cause of death. Inj Prev 2012;18:360-4.

21. Stevenson M, Hung DV, Hoang TH, et al. Evaluation of the Vietnamese A6 mortality reporting system: all-cause mortality. Asia Pac J Public Health 2015;27:733-42.

22. General Statistic Office of Vietnam. The 2009 Vietnam population and housing census: Completed results. Available: http://www.gso.gov.vn/default_en.aspx?tabid=476\& idmid=\&ltemlD=10802 [Accessed Mar 2018].

23. Wagner AK, Soumerai SB, Zhang F, et al. Segmented regression analysis of interrupted time series studies in medication use research. Journal of Clinical Pharmacy and Therapeutics 2002;27:299-309.

24. Higgins JPT, Thompson SG, Deeks JJ. Measuring inconsistency in meta-analyses. BMJ 2003:327:557-60.

25. Bernal JM, Cummins S, Gasparrini A. Interrupted time series regression for the evaluation of public health interventions: A tutorial. International Journal of Epidemiology 2016;0(0:1-8.

26. Peng $Y$, Vaidya N, Finnie $R$, et al. Universal motorcycle helmet laws to reduce injuries: a community guide systematic review. Am J Prev Med 2017;52:820-32.

27. Lee JM. Mandatory helmet legislation as a policy tool for reducing motorcycle fatalities: Pinpointing the efficacy of universal helmet laws. Accid Anal Prev 2018;111:173-83.
28. Araujo M, Illanes $\mathrm{E}$, Chapman $\mathrm{E}$, et al. Effectiveness of interventions to prevent motorcycle injuries: systematic review of the literature. International Journal of Injury Control and Safety Promotion 2017;24:406-22.

29. Urie Y, Velaga NR, Maji A. Cross-sectional study of road accidents and related law enforcement efficiency for 10 countries: a gap coherence analysis. Traffic Inj Prev 2016;17:686-91.

30. Chliaoutakis JE, Gnardellis C, Drakou I, et al. Modelling the factors related to the seatbelt use by the young drivers of Athens. Accid Anal \& Prevention 2000;32:815-25

31. Papadakaki M, Tzamalouka G, Orsi C, et al. Barriers and facilitators of helmet use in a Greek sample of motorcycle riders: which evidence? Transp Res Part F: Traffic Psychol Behav 2013;18:189-98.

32. Haqverdi MQ, Seyedabrishami S, Groeger JA. Identifying psychological and socioeconomic factors affecting motorcycle helmet use. Accid Anal Prev 2015;85:102-10.

33. Russo BJ, Barrette TP, Morden J, et al. Examination of factors associated with use rates after transition from a universal to partial motorcycle helmet use law. Traffic Injury Prevention 2017; 18:95-101.

34. Ngo AD, Rao C, Phuong Hoa N, Hoa NP, et al. Road traffic related mortality in Vietnam: evidence for policy from a national sample mortality surveillance system. BMC Public Health 2012;12. 